\title{
Experiences of fatigue in daily life of people with acquired brain injury; a qualitative study.
}

Leisle Ezekiel, Leanne Field, Mary Boulton, Johnny Collet, Helen Dawes

Keywords: brain injuries; fatigue; social participation, self-management, coping Word count 6359.

\begin{abstract}
Purpose

To develop an in-depth understanding of how survivors of acquired brain injury (ABI) experience fatigue and how fatigue affects everyday life.
\end{abstract}

\section{Materials and methods}

We conducted semi-structured in-depth interviews with 16 adults with ABI fatigue, recruited from support groups in south east UK. Interviews were analysed using the frameworks method.

\section{Results}

We developed four themes: experiencing fatigue in the context of everyday activities, struggling to make sense of fatigue, coping with fatigue, adjusting social participation in the context of fatigue. Fatigue was comprised of mental, physical, generalised and motivational fatigue. Balancing fatigue against participation in daily activities was influenced by coping strategies and social support. Opportunities to socialize or participate in meaningful activities provided incentives for participants to push through their fatigue.

\section{Conclusions}

This study highlights complex interactions that potentially mitigate the impact of fatigue on everyday life. Educational and self-management approaches to fatigue need to account for different types of fatigue in the contexts of an individual's daily activity. Assessment of fatigue should capture in- the- moment experiences of different types of fatigue and activity. 
Social support and participation in meaningful activities may help individuals to break the negative cycle of fatigue and inactivity.

(196 words).

\section{Implications for rehabilitation}

- Assessment of fatigue after brain injury should capture the multidimensional nature of fatigue as well as contextual information about exacerbating activities and environments.

- Development of personalised coping strategies that account for perceived triggers of different subtypes of fatigue may help ABI survivors to broaden their activity and social participation.

Social support and opportunities to participate in personally meaningful activities may help prevent or break a negative cycle of fatigue and inactivity for some ABI survivors

\section{Introduction}

Acquired brain injury (ABI) most commonly arises following stroke, traumatic brain injury or oxygen deprivation and is a major cause of disability in the UK[1]. In 2016/17, 348,453 people were admitted to hospital in the UK following an ABI, equivalent to 533 per 100,000 of the population [2]. Problematic and persistent fatigue is frequently experienced by survivors of acquired brain injury. Estimates of the prevalence of fatigue in this group range from 27 to $73 \%[3,4]$, with a significant proportion still experiencing fatigue six or more years after their brain injury $[5,6]$.

As a clinical symptom, fatigue is a complex phenomenon that is difficult to define as it overlaps with lay concepts of tiredness. In addition, it is difficult to distinguish fatigue from the effects of comorbid conditions such as depression and sleep dysfunction [7] [8]. There is 
also a lack of consensus on theoretical definitions of both post stroke fatigue and post TBI fatigue [7]. However, the term central fatigue is increasingly used to describe fatigue after acquired brain injury, with "central" denoting a central nervous system origin [4,9-12]. Chaudhuri and Behan [13] defined central fatigue as "the failure to initiate and/or sustain attentional tasks ('mental fatigue') and physical activities ('physical fatigue') requiring selfmotivation (as opposed to external stimulation)" p35. Central fatigue is characterised by feelings of exhaustion, increased perception of effort and difficulty with sustained motivation [9]. The concept of central fatigue accounts for both the experience of fatigue and for fluctuations in fatigue severity arising from different levels of stimulation or effort. Consequently, this definition of fatigue is useful when considering fatigue after brain injury because it encapsulates multiple dimensions of fatigue and captures a range of fatigue related behaviours [14].

Fatigue is known to be a barrier to acquired brain injury (ABI) survivors' engagement in social, leisure and physical activities, as well as resumption of work [15-19]. Several qualitative studies found that those living with fatigue post brain injury tended to reduce their physical and social activities and to increase their sedentary and home based activities [20,21]. This means that physical activity levels for ABI survivors tend to be lower than those recommended by physical activity guidelines, particularly with regards to moderate or vigorous activity $[16,22,23]$. The benefits of physical activity and social engagement to health and wellbeing in the general population are well established so it is concerning that a significant proportion of $\mathrm{ABI}$ survivors experience long term difficulties in these areas $[24,25]$.

Clinical guidance to address problematic and persistent fatigue after ABI currently recommends educational and self- management approaches to managing fatigue [26] despite 
limited evidence to support these approaches in the brain injury population [27]. Activity scheduling is recommended as part of self management of fatigue [28] but current approaches to understanding an individual's daily experience of fatigue and activity are limited. Self report fatigue scales and activity diaries are used to gather information about an individual's experience of fatigue. However, fatigue scales reflect a summation of an individual's fatigue experience and activity diaries are unreliable when completed retrospectively [29] [30] . A more in-depth understanding of the way ABI survivors perceive and manage their fatigue is required and it is therefore vital that we explore how living with fatigue shapes ABI survivors' participation in everyday activities as well as the strategies used to cope with fatigue in everyday life.

\section{Research aims}

This study aimed to develop an in-depth understanding of how ABI survivors experience and cope with fatigue and how fatigue affects their everyday lives.

\section{Methods}

Design

We conducted a descriptive qualitative study within the constructivist paradigm of participants' experiences of fatigue after acquired brain injury. In the constructivist paradigm, knowledge is constructed by individuals as they make sense of their experiences. This means there are multiple social constructions of meaning and knowledge which can only be known through understanding individuals' lived experience[31]. Hence, we elicited participant's accounts of their fatigue experiences through semi structured interviews. The study was approved by the Oxford Brookes University Research Ethics Committee. 


\section{Research team}

All interviews were conducted by LE (lecturer in occupational therapy with an MRes in Social Research) who has previous experience of qualitative interviewing and of working with people with brain injury. MB is a Professor in Health Sociology and experienced in the use of Framework as a method of analysis. LF is a research assistant, studying for a BSc in Occupational Therapy.

\section{Recruitment of study participants}

Participants were recruited from five stroke and head injury support groups across three counties in England using a purposive sampling strategy to capture people with a broad range of fatigue experiences after brain injury. We aimed to recruit adults of working age or retired, with different types of acquired brain injury, at varying times post brain injury. Individuals were eligible to participate in the study if they were aged 18 or over, reported problematic fatigue following acquired brain injury, were able to give informed consent and able to communicate sufficiently to participate in an interview.

Individuals were excluded if they had a diagnosis of another health condition which caused fatigue, were taking medication that caused significant fatigue, were unable to give informed consent, or unable to communicate sufficiently to participate in an interview. Participants were recruited between December 2015 and April 2017.

\section{Data collection}

Written informed consent was obtained from each participant prior to data collection. Semi structured interviews were conducted and questionnaires completed either at the persons home or in a private space at the relevant day service. LE interviewed all participants using a flexible semi-structured interview guide [32]. The semi-structured interview guide was developed following consultation with $\mathrm{ABI}$ survivors to address the research question and 
objectives. It consisted of open questions and prompts organised around three key topics: experiences and manifestations of fatigue, impact of fatigue on daily routines and activities, and adapting to living with fatigue. Interviews lasted between 15 and 90 minutes and were audio recorded and then transcribed by LE and LF.

Participants also completed three questionnaires: a short demographic questionnaire which included participant's gender, age, length of time since brain injury and type of injury, home circumstances and employment status; the fatigue severity scale [33]; and the EQ5D-5L health questionnaire [34].

The fatigue severity scale (FSS) measures the degree to which fatigue interferes in everyday life [35]. It has good psychometric properties [36] and is suitable for use with people with acquired brain injury [37,38]. The FSS consists of nine questions and is scored on a seven point Likert. A mean score of four or more indicates fatigue severity above that expected in healthy populations [38].

The EQ-5D-5L is a health-related quality of life questionnaire which measures perceived health overall and problem severity across five domains (mobility, self-care, usual activities, pain/discomfort and anxiety/depression.) The EQ-5D-5L is scored on a five point Likert scale and has been validated for use with people with long term health conditions, including stroke [39].

Interviews were analysed concurrently with recruitment. After 16 interviews, LE reviewed the data to establish whether data saturation had been achieved and the research objectives met. As no new codes had been added for the final three interviews, the decision was taken to end recruitment.

\section{Data Analysis}


Interview transcripts were analysed using the Framework Method [40] and data were managed in NVIVO. The Framework Method is a type of thematic analysis that involves the reduction of interview data into matrices and enables the researcher to analyse data within and across participants [40]. It is a rigorous and systemic approach to data analysis that involves five stages: familiarisation with the data, identifying an analytical framework to code the data, indexing (applying codes), charting (summarising interview data under themes), mapping and interpretation [40]. The Framework method is a suitable approach for research where the analysis may be both inductive and deductive [41].

Interviews were transcribed by LE and LF and then checked for accuracy against the audio recording. LE and MB independently coded the first five interviews and then compared and discussed coding. Through this discussion, codes were grouped together into categories (broad categories and sub-categories) and these categories formed the initial analytical framework. The framework categories were also informed by the topics within our interview guide. The framework was piloted on the first three interviews and then further refined through peer debriefing with MB. LE then applied the revised analytical framework to all interviews and any new codes arising from subsequent interviews were added to the framework. Once the final analytical framework had been applied to each interview, LE created five matrices, one for each broad category. The broad categories were; experiences and effects of brain injury, contexts in which fatigue was experienced, how fatigue was experienced, responses to being fatigued, the effects of fatigue on daily life. Each matrix consisted of columns of subcategories and rows which corresponded to each interview. For each interview, all data within each subcategory were charted into the corresponding cell of the matrix (see table 1). This process reduces the data and allows the researchers to look for patterns in the data and analyse the data across and within cases. During the process LE looked for patterns in how fatigue was experienced over time, configurations of contexts that 
shaped the impact of fatigue on daily life, and patterns in the manifestation of fatigue. For each matrix LE then examined the charted data and identified dimensions of the data which were then grouped into broader themes (see table 2).

Table 1: Example of the charting stage of Frameworks method: excerpt of charted data within the 'Contexts of fatigue experiences' matrix.

\begin{tabular}{|c|c|}
\hline Subthemes & $\begin{array}{l}\text { Interview transcript: participant } 8 \text { : age } 20-29 \text {, traumatic } \\
\text { brain injury, more than } 5 \text { years post injury }\end{array}$ \\
\hline $\begin{array}{l}\text { Perceived causes of } \\
\text { fatigue. }\end{array}$ & $\begin{array}{l}\text { Walking with balance problems makes him tired. Traveling to } \\
\text { Headway on buses as well. Being in "really noisy places" is } \\
\text { tiring. Using the laptop to do tasks for charity }\end{array}$ \\
\hline $\begin{array}{l}\text { Contexts where } \\
\text { fatigue is not } \\
\text { experienced }\end{array}$ & Not discussed \\
\hline $\begin{array}{l}\text { Fatiguing Cognitive } \\
\text { activities }\end{array}$ & $\begin{array}{l}\text { Using the laptop, trying to remember how to do things is } \\
\text { tiring. } \\
\text { Working on the checkout at the supermarket. "I get really } \\
\text { tired and then my concentration my focus starts to dip." }\end{array}$ \\
\hline $\begin{array}{l}\text { Fatiguing physical } \\
\text { activities }\end{array}$ & $\begin{array}{l}\text { Walking tires him out so he uses buses a lot. "I can't really } \\
\text { afford not doing that cause it's my only way of getting about". } \\
\text { Doesn't do a lot of sport because that tires him out also. }\end{array}$ \\
\hline $\begin{array}{l}\text { Experiences of fatigue } \\
\text { at work. }\end{array}$ & $\begin{array}{l}\text { Working at the checkout at a local supermarket. Got really } \\
\text { tired and found concentration difficulty. Struggles to keep } \\
\text { focus and not be distracted. }\end{array}$ \\
\hline
\end{tabular}

Table 2: Example of interpretation stage of Frameworks method: higher order abstraction of data analysis. 


\begin{tabular}{|l|l|l|l|l|}
\hline Interview & $\begin{array}{l}\text { Charting of interview in } \\
\text { subtheme: perceived causes of } \\
\text { fatigue }\end{array}$ & Elements & Dimensions & Theme \\
\hline $\begin{array}{l}\text { Participant } \\
8\end{array}$ & $\begin{array}{l}\text { Walking with balance problems } \\
\text { makes him tired }\end{array}$ & $\begin{array}{l}\text { balance affects } \\
\text { fatigue }\end{array}$ & $\begin{array}{l}\text { Interaction } \\
\text { between } \\
\text { impairment and } \\
\text { fatigue. }\end{array}$ & $\begin{array}{l}\text { Struggling to } \\
\text { make sense of } \\
\text { fatigue }\end{array}$ \\
& $\begin{array}{l}\text { Traveling to Headway on buses as } \\
\text { well. } \\
\text { Being in "really noisy places" is } \\
\text { tiring. }\end{array}$ & $\begin{array}{l}\text { Travelling on public } \\
\text { transport. } \\
\text { Being in public } \\
\text { places. } \\
\text { Physical activity } \\
\text { Environment - } \\
\text { noise } \\
\text { Cognitive } \\
\text { activities }\end{array}$ & $\begin{array}{l}\text { Fatigue in the } \\
\text { context of } \\
\text { everyday } \\
\text { activities. }\end{array}$ \\
$\begin{array}{l}\text { Using the laptop to do tasks for } \\
\text { charity work. }\end{array}$ & Using the computer. \\
\cline { 2 - 5 } & $\begin{array}{l}\text { Doing too much at } \\
\text { once, yeah I get quite tired". }\end{array}$ & $\begin{array}{l}\text { Overexertion } \\
\text { once }\end{array}$ & $\begin{array}{l}\text { Struggling to } \\
\text { make sense of } \\
\text { fatigue }\end{array}$ \\
\hline
\end{tabular}

\section{Trustworthiness}

Peer review of the qualitative data analysis, an audit trail and a reflexive diary were used to ensure that the analysis was true to the interview data. LE discussed the analysis and decision making with MB throughout the analytical process. LF audited the analytical process by tracking themes back to the transcripts and examined how representative the themes were of the original data.

\section{Results}

\section{Characteristics of participants.}

Seventeen people agreed to participate in the study; one interview was not usable due to technical issues. Participants ranged from 28 to 79 years old and time since ABI ranged from six months to 28 years. Ten participants had experienced stroke, two both stroke and traumatic brain injury, and four had experienced traumatic brain injury (see table 3). Results 
from the EQ-5D-5L show that participants experienced problems across a range of daily

functions (fig 1). Four participants were still receiving physiotherapy or occupational therapy.

Only two participants described being advised on how to manage their fatigue.

Table 3. Demographic information of participants.

\begin{tabular}{|c|c|c|c|c|c|c|c|}
\hline $\begin{array}{l}\text { Participa } \\
\text { nt }\end{array}$ & Age & $\begin{array}{l}\text { Gender } \\
\text { (male } \\
\text { /female) }\end{array}$ & $\begin{array}{l}\text { Time } \\
\text { since } \\
\text { ABI }\end{array}$ & $\begin{array}{l}\text { Type of } \\
\text { ABI }\end{array}$ & $\begin{array}{l}\text { Lives alone } \\
(\mathrm{Y} / \mathrm{N})\end{array}$ & $\begin{array}{l}\text { Works } \\
\text { status }\end{array}$ & $\begin{array}{l}\text { Mean score of } \\
\text { fatigue severity } \\
\text { scale* }\end{array}$ \\
\hline 1 & 72 & $\mathrm{~F}$ & $\begin{array}{l}\text { Six } \\
\text { months }\end{array}$ & stroke & $\mathrm{n}$ & retired & 6.9 \\
\hline 2 & 48 & $\mathrm{~F}$ & $\begin{array}{l}11 \\
\text { months }\end{array}$ & stroke & $\mathrm{n}$ & $\begin{array}{l}\text { unable to } \\
\text { work }\end{array}$ & 6 \\
\hline 3 & 76 & M & 28 months & stroke & $\mathrm{n}$ & retired & 6 \\
\hline 4 & 66 & M & 5 years & stroke & $\mathrm{n}$ & retired & 8 \\
\hline 5 & 79 & $\mathrm{~F}$ & 4 years & stroke & $\mathrm{n}$ & retired & 4.8 \\
\hline 6 & 55 & M & 24 years & TBI & $\mathrm{y}$ & retired & 4.2 \\
\hline 7 & 64 & $\mathrm{~F}$ & 4 years & stroke & $\mathrm{n}$ & $\begin{array}{l}\text { Self } \\
\text { employed }\end{array}$ & missing data \\
\hline 8 & 28 & M & 16 years & TBI & $\mathrm{n}$ & $\begin{array}{l}\text { unable to } \\
\text { work }\end{array}$ & 6 \\
\hline 9 & 66 & M & 4 years & stroke & $\mathrm{n}$ & retired & 7.8 \\
\hline 10 & 60 & M & 28 years & stroke & $\mathrm{y}$ & $\begin{array}{l}\text { unable to } \\
\text { work }\end{array}$ & 3.7 \\
\hline 11 & 71 & $\mathrm{Ma}$ & 19 years & TBI & $\mathrm{n}$ & $\begin{array}{l}\text { unable to } \\
\text { work }\end{array}$ & 5.2 \\
\hline 12 & 37 & M & 8 years & TBI & $\mathrm{n}$ & employed & 3.7 \\
\hline 13 & 55 & M & 5 years & $\begin{array}{l}\text { TBI and } \\
\text { SAH }\end{array}$ & $\mathrm{y}$ & $\begin{array}{l}\text { Unable to } \\
\text { work }\end{array}$ & 5.2 \\
\hline 14 & 60 & $\mathrm{~F}$ & 4 years & stroke & $\mathrm{n}$ & retired & 5.1 \\
\hline 15 & 59 & M & 11 years & stroke & $\mathrm{y}$ & retired & 6.2 \\
\hline 16 & 52 & M & 5 years & $\begin{array}{l}\text { stroke } \\
\text { and TBI }\end{array}$ & $\mathrm{y}$ & $\begin{array}{l}\text { Unable to } \\
\text { work. }\end{array}$ & 6.4 \\
\hline
\end{tabular}

*Score of 4 or more indicates problematic fatigue. 
Figure 1: summary of participants scores on domains of EQ-5D-5L.

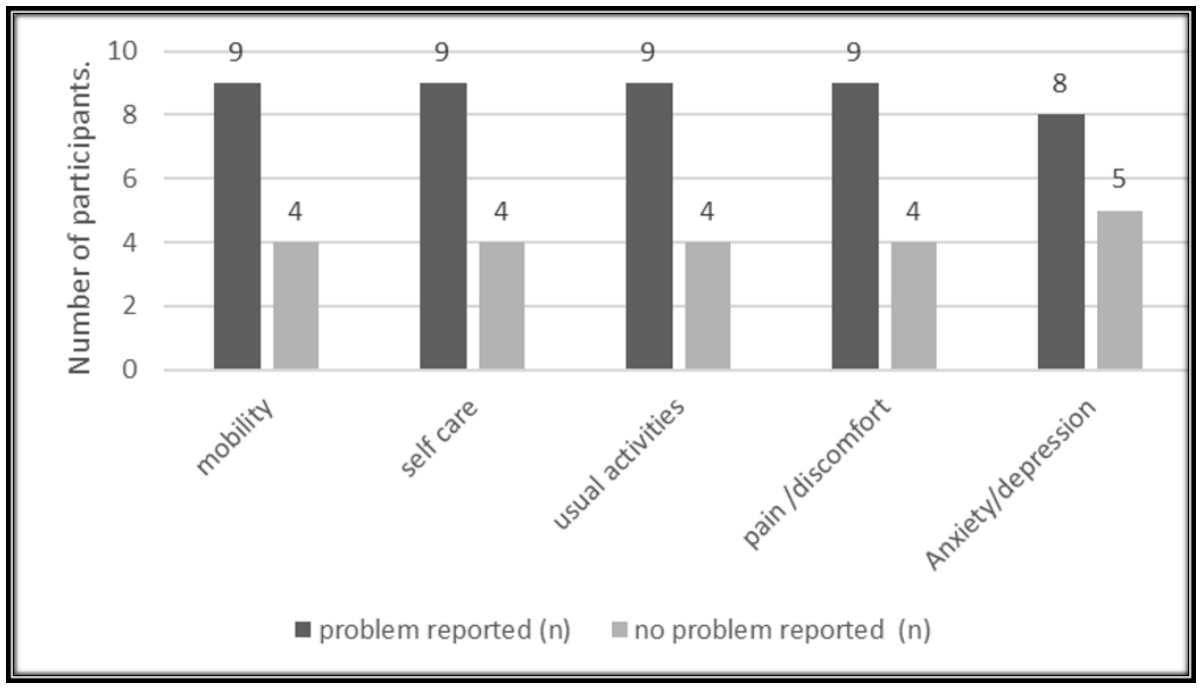

\section{Interview themes}

We derived four major themes from our analysis of the interview data. These were:

experiencing fatigue in the context of everyday activities, struggling to make sense of fatigue, coping with fatigue, adjusting social participation in the context of fatigue

\section{Experiencing fatigue in the context of everyday activities.}

Most participants reported that what they did (activities) and where they did them (environments) shaped their experience of fatigue. Specific features of activities and environments that worsened or lessened their fatigue were identified. Only one participant was unable to do so because he identified fatigue as "always there" (Participant 10). For many of our participants, everyday physical activities (for example, a short walk or light gardening task) now seemed to exacerbate fatigue.

"But just getting dressed, I am worn out, simple tasks... which everyone just takes for granted”. (Participant 1, female, aged 71, stroke). 
Participants also felt fatigue during sedentary activities such as using the computer, reading, writing or completing administrative tasks. All these tasks led to mental fatigue as they involved focused attention, information processing or multitasking. Coping with distractions and being interrupted whilst concentrating also worsened fatigue.

"Umm distractions. I worked in an office upstairs on my own, and everyone else was downstairs. I'd start doing one particular job, part of a job, I'd get a phone call and so it's coming away and dealing with that. And I would have to really concentrate to think to go back to what I was doing. And then it's constant". (Participant 2, female, aged 48, stroke).

In contrast, two participants described how physical exercise helped them to cope with their fatigue. Participant 13 found that exercise tired him physically and this helped with his mental fatigue. Another felt energised after exercise.

"But I was getting home [from the gym] and thinking oh I must do this; I must do that. More of an incentive to do something. It must be something to do with the exercise. Because even though I was tired I had more get up and go in me”.

Participant 13, male, 55, TBI)

Features in their environment such as artificial lighting, background noise and crowds also made fatigue worse. Participants struggled to follow conversation when music was playing or several people were talking and were fatigued by the effort of concentrating.

I really don't like going shopping because there are too many people coming at me in all directions. I just can't cope with watching everyone. With crowds I can't cope with all the different sounds and voices, trying to listen to everyone. I just can't manage it anymore and it whacks me out. (Participant 4, male, aged 66, stroke).

A few participants identified environments such as the support group they attended that they found relaxing or supportive and that offered temporary relief from fatigue. 
"So the swimming pools are warm and then you've got beds you can sit on and have a cup of tea and cake. There's something also about the fact that it's relaxing".

(Participant 2, female, aged 48, stroke).

\section{Struggling to make sense of fatigue}

Our participants often struggled to makes sense of their experiences as fatigue was both predictable and at times unpredictable, with variability in severity and the type of fatigue experienced. Many participants were able to identify triggers that usually worsened their fatigue and often attributed their fatigue to "overdoing it". Fatigue affected participant's physical and cognitive performance as well as their social interactions with others.

The severity of fatigue fluctuated over the course of a day or sometimes over several days. Many participants experienced fatigue in the middle of an activity or social event, whereas others described a sense of fatigue building over the week. One participant used a battery powered toy analogy to explain how his fatigue seemed to build up over several days but each day his energy level dropped lower than before until finally, he had no energy left.

"It starts off, pretty good. And you've got the power, but you gradually use up your power. And as each day's amount of power you get dips, and you recharge, by sleeping. Dip. Like that. And it goes down and away. And then I'll end up, having a day in bed”. Participant 16, male, aged 52, stroke and TBI).

Others perceived fatigue to be sudden and overwhelming, forcing them to stop and rest.

"You are running at 90 mile an hour and all of a sudden something's there and you just bang and you are on the floor. Just everything drains. It's like turning a tap on in your ankle and feeling everything draining out of you slowly. So by the end of it there is literally nothing left. (Participant 2, female, aged 48, stroke).

Several participants were able to distinguish between mental or physical fatigue, whereas others experienced fatigue that was all encompassing and difficult to describe. Several 
participants described difficulty motivating themselves and found they procrastinated more. They described "not wanting to do anything" or needing to marshal their mental resources when faced with a demanding task. At times this experience was complicated by the person's disability as everyday tasks became more effortful.

"I just can't be bothered, you know? I'd rather sit and watch some pointless thing on the TV than actually get up and do anything. And I think a lot of it is because to do anything is difficult. It's not as easy one handed. But there's a lot of one-handed people about and they manage. It's Just this feeling of I can't be bothered really. I'd rather sit here" (Participant 5, female, aged 79, stroke).

When feeling fatigued, participants noticed changes in their thought processes, communication and movement. These changes were sometimes related to impairments that had resulted from their brain injury. For example, participant 16 noticed how the hemiparetic side of his body weakened as he fatigued.

"The more tired I get, the more I lean to the right. Like, when I'm sat down, relaxing, I start going over to the right. But, when I'm fatigued I really go over and like, I can't sit upright” (Participant 16, male, aged 52, stroke and TBI).

Participants also found that fatigue negatively affected their ability to concentrate, process information or multi-task.

Well I think, I think it's possibly the fact that I do stop communicating. And er I keep on walking down the road with my wife, when she talks to me I can't concentrate on the two things, walking and talking. So that's, I know I am getting tired and need a rest. (Participant 4,male, aged 66, stroke).

Other participants found fatigue affected their mood and they became irritable or were frustrated. Sometimes irritability was the first sign of fatigue. 
I suppose it most probably manifests its self initially in annoyance. Which may be accounts for some of the anger. Annoyance that I am feeling tired, annoyance that I can't do as much as I had done previously.. its frustration that's its happening to me again and then thinking ok that I've got to give into it because my body is telling me that I am tired. And I must be tired even if its not physically its mentally. (Participant 9,male, 66, stroke).

\section{Coping with fatigue}

Participants employed a wide range of strategies to cope with fatigue including both proactive strategies directed at minimising future fatigue and reactive strategies directed at recovering from fatigue.

Proactive strategies. Participants used proactive strategies to reduce the impact of fatigue on daily life by balancing the demands made on them against their available physical and mental resources. However, effective use of proactive strategies depended on the person's ability to predict how effortful they might find an activity or event to be. This was sometimes hampered by memory impairments and by the fluctuating nature of fatigue which meant that achieving a satisfactory balance between activity and fatigue was an ongoing challenge.

"I'm sort of, four and a half years in, and I'm still learning really to try and balance the tired-the fatigue, and what I want to do. And, what I want to do, right, is higher the fatigue levels [allow]." (Participant 16, male, aged 52, stroke and TBI ).

Proactive strategies involved planning and prioritising their activities, avoiding fatiguing situations, pacing themselves, and planning rests or short daytime "naps".

“I try to pace myself, it doesn't always work, having never done it before. But if you listen to your body then yes, I do have to take breaks during the day. (Participant 14, female, aged 60, stroke). 
One participant stressed the importance of rest, hydration and diet in maintaining sufficient energy levels (Participant 12, male, 37, TBI).

Reactive strategies. All participants used rest or sleep to recover from their fatigue. Resting could mean sitting quietly for half an hour or resting in bed for a whole day, depending on the severity of the fatigue. Some participants also identified restorative activities such as listening to a relaxation track or browsing on their computer.

In situations where fatigue had become overwhelming, participants tended to use sleep to recover. For some a short nap would suffice, whereas others needed to sleep for several hours. Participant 3 described the difference between "nipping it in the bud" and "hitting a brick wall": with the former she required a short rest and with the latter she would need to lie down and sleep.

"If I have washed the floor perhaps, I will come and have a sit down and perhaps get the laptop out just go on the laptop and just go on eBay or something like that. And I am there for half an hour and will help me get my mind back in. You know it's not really doing anything just window shopping. (Participant 4, male, aged 66, stroke). Participants who used sleep as their main reactive strategy seemed to have less control over their fatigue. They described a lack of predictable routine as they slept during the day and were awake for extended periods at night. They then found themselves out of step with the outside world.

"But now, I seem to have my days and nights mixed up. Sort of um, sleep all day and sort of have broken sleep at night. Which isn't a surprise. I'd already had seven or eight hours sleep in the day. " Participant 10, male, aged 60, stroke).

Continuing despite fatigue. For many of our participants, living with fatigue also meant knowing when to accept their fatigue and when to "push through" it. Participants described "keeping going for a few hours" but would then need to "wave the flag" to recover (participant 16, male, 52, stroke and TBI). Participants pushed through their 
fatigue for different reasons. Sometimes it was necessary because they wanted to attend a social event important to them, or because there was something they had to do and they didn't want to disappoint friends or family. At other times, they simply did not want to give in to their fatigue.

"I'm not going to not do something because I going to get tired. I would rather go for a walk for an hour, um and yes come home and need to lie down for an hour than sit here and not do anything" (Participant 2, female, aged 48, stroke).

Other participants acknowledged that having "something to do" or the presence of another person, helped them to push through their fatigue but those who were alone, without any planned meaningful activities or events, could find this more difficult.

"I spend a lot of time, too much time in bed because I ain't going anywhere. I just lie in bed. I've got the TV and computer next to me. If I get up, all I do is go and sit on the settee so I think what's the point?" (Participant 13, male, age 55, stroke).

\section{Adjusting social participation in the context of fatigue.}

Both fatigue and coping with fatigue had significant impacts on social participation. Participants described a process of balancing the risk of fatigue against doing what they needed or wanted to do. Their need to rest or sleep when fatigued was also factored into the process as participants cleared their schedule so they could rest before and after an event. This required them to make stark choices about how they spent their time. Socialising with others in particular was affected by fatigue, often because participants found social settings tiring as they struggled to focus on and follow conversations.

"We don't do a lot of socialising now. I can't take the noise; my brain can't filter the noise. Erm, we don't go to the cinema anymore. Again, I can't take the noise. Um I can't take crowds - is a great problem for me. .. it's a battle. But we just grin and bear it. And bite the bullet and just get on with it." (Participant 14, female, aged.60, stroke). 
Some participants found ways around difficulties in socialising. They met friends at home or planned social events for earlier in the day. Others limited their contact with family members and found ways to exit the situation when they were tired. Participants with younger grandchildren all commented on how fatigue limited both what they could do with their grandchildren and how much time they could spend with them.

"And I get, like with my little grandchildren, I get a great deal of pleasure out of them... But, after about two, two and a half hours, I need to be away from them, so I go and sit in the other room. Um, they can't understand it of course, bless them. But they um, you know it's just too much, to take it all in".(Participant 11, male, 71, brain injury).

Poignantly, participants found they were no longer able to take part in activities previously shared with family members and friends. This was exemplified by participant 2 , talking about her daughter.

"for many years I've worked backstage at every show they've (daughter and friends) ever done. No way I could handle all that [now] ... I would love to go back to the cinema, I and my daughter were always at the pictures. There's not a film that I know that I could go and watch on the big screen with the noise.". (Participant 2, female, aged 48 , stroke).

Three participants felt that their fatigue prevented them from going back to work. Another participant was able to work part-time but found it made a significant impact on his life outside work. Participant 12 maintained his part time job by following a set routine of early nights and by limiting his participation in other activities. To place this in context, he described needing eleven hours sleep at night and a rest at midday to work for three hours a day as a cleaner. 
"Before I used to be a right lad around town, with my friends. We used to often be out late at night. But I can't do that anymore, I have to manage myself, just managing your sleep early ... About half past nine (evening) “. (Participant 12, male, aged 37, brain injury).

\section{Discussion}

In this study we have explored the experiences of people living and coping with fatigue after an acquired brain injury, in the context of their daily lives. We found ABI fatigue to consist of sub types of fatigue which were differentially associated with specific activities, events or environments. We have also extended previous research on coping with fatigue by examining how strategies used to manage fatigue and incentives to overcome fatigue related to an individual's perception of coping.

Subtypes of fatigue experienced in the context of daily activities.

In line with other studies we found that fatigue after ABI substantially affects an individual's participation in leisure, community, social and work activities [23] [21,42]. However, this study also demonstrates how the experience of fatigue among ABI survivors may be comprised of several different types of fatigue: mental, physical, generalised and motivational fatigue (i.e. a decline in the willingness to exert further effort) [43]. The experience of physical and mental fatigue seems to be distinct from generalised fatigue or motivational fatigue. Physical and mental fatigue were both attributed to specific contexts. Physical fatigue was attributed to physical activity whereas mental fatigue was associated with activities or environments that taxed cognitive processes such as information processing (for example finding their way in a busy supermarket), dual- or multitasking (such as holding a conversation whilst getting dressed) and focused attention, as is often needed in a social setting. This suggests that different types of fatigue may affect different areas of 
participation and that the composition of overall fatigue may vary from one individual to another.

Several cohort studies have also reported the presence of these different types of fatigue after brain injury, as measured by multidimensional fatigue scales [44-46]. These studies reported varied results as to which type of fatigue, physical or mental fatigue, was most prominent whilst motivational fatigue was reported as less pronounced than other types of fatigue. The attribution of excessive fatigue to specific activities or situations (for example socialising, physical exertion or coping with noisy environments) has been reported in previous qualitative studies $[19,23,47]$. However, a causal relationship between daily activity and fatigue has not yet been established in quantitative studies. Several large cohort studies were unable to demonstrate significant relationships between fatigue and participation in daily activities or fatigue and physical activity [5,48-52]. It has been previously argued that fatigue changes how an individual participates in daily activities rather than the frequency of activity and hence the effect of fatigue would not be shown by comparing fatigue scores against measures of daily activity [50]. In our study, some ABI survivors adapted activities to avoid exacerbating fatigue, for example meeting friends at home rather than in a public place. These changes may be too subtle to be measured by an activity scale but may have significant consequences for the individual in terms of their satisfaction with participation and quality of life [50].

In addition, difficulty in establishing a relationship between activity and fatigue may be due to ways in which fatigue is defined and measured. Most fatigue scales provide a summation of fatigue which is likely to reflect the propensity of an individual to experience fatigue rather than fatigue that arises in the moment (state fatigue) [29]. State fatigue is likely to be more closely related to changes in activity and behaviour, as suggested by our findings [29]. Hence assessing fatigue and activity as they occur throughout the day may help to establish the 
nature of the relationship between fatigue and activity. This is important because the assumption that what individuals do affects their fatigue underpins many fatigue management strategies.

Taken together, these findings suggest that it may be more helpful to view fatigue as an umbrella term that includes subtypes of fatigue, recognising that each sub-type may have different symptoms and consequences for participation in daily life [11] and may require different approaches to intervention approaches [53].

Balancing fatigue and participation in daily life.

We found participants were engaged in an ongoing process of balancing their fatigue against their participation in daily activities and the efficacy of this process formed a continuum. At one end of the continuum, participants were mostly satisfied with the balance they achieved and felt fatigue was under control. At the other end, participants felt fatigue dominated their life and they struggled to cope. The types of strategies used to overcome fatigue and the specific incentives for wanting to do so may influence how well controlled an individual perceives their fatigue to be.

Strategies to manage fatigue. In line with other qualitative studies of living with fatigue, we found that strategies such as daytime sleep, resting, avoidance of triggers and pacing, were frequently used to mitigate the impact of fatigue [19-21]. However, we noted that those who perceived themselves as unable to cope with fatigue relied predominantly on reactive and avoidance strategies, reported less structure in their daily routine, described limited social participation and often lived alone. This finding challenges Eilertsen et al [20] who suggested that difficulties coping with fatigue arose because strategies such as rest and sleep were not sanctioned socially and were therefore resisted. However, rather than resisting sleep, 
our participants were often overwhelmed by their need to sleep, which then limited their engagement in everyday activities [21].

We were unable to determine whether reliance on reactive strategies (particularly daytime sleep) occurred because of the severity of fatigue or whether other factors (such as social isolation, lack of meaningful roles or the complexity of disability experienced) contributed to a negative cycle of fatigue and overuse of reactive strategies. Nor is it clear which comes first: lower levels of activity and social participation or reliance on predominately reactive coping strategies. However, social support and social contact have been linked to coping styles, so it seems likely that the relationship between social participation and coping strategies is reciprocal $[54,55]$. Further research is needed to understand these different patterns of response to fatigue and to determine whether levels of activity and participation are potentially useful targets for therapeutic interventions for fatigue [45].

Incentives to overcome fatigue. For many of our participants, opportunities to take part in activities or events that were enjoyable, rewarding or involved another person, sometimes provided incentives to push through fatigue, to keep active around the home or to participate in an event that would otherwise be too daunting. Kirkevold et al [47] also described how being mentally and physically active was used to transform and overcome fatigue after stroke.

Our findings highlight how living with others is beneficial in maintaining activity levels and social participation as it provides reasons for individuals to overcome fatigue on a daily basis. But living with others also complicates the management of fatigue as ABI survivors strive to be a productive member of the household, whilst hiding their fatigue from others. Eilertsen et al [20] described how stroke survivors were distressed by high expectations of family members whilst Norrie et al [56] found that a third of family members or significant others viewed the person as lazy. Both authors suggest that the behaviours and beliefs of significant 
others are detrimental to those struggling with fatigue. Several of our participants worried about being a burden to their family or partner and so tried to do as much as they could to relieve the burden.

However, it seems likely that pushing through fatigue is an important part of learning to manage fatigue in the longer term and the cumulative effect of increasing activity levels may help to reduce levels of fatigue [45]. An effective balance between activity and fatigue is often difficult to achieve, with ABI survivors fluctuating between doing too much or too little [47]. Hence ABI survivors and those that support them would benefit from education about how best to manage their fatigue whilst gradually increasing their activity levels. Further research is needed to establish whether interventions focused on education, strategy use, and utilising social support would reduce the long-term impact of fatigue of participation.

\section{Strengths and Limitations}

A key strength of this study was the diversity within the participant group with regards to type of brain injury and the length of time since brain injury. This enabled us to examine a broad range of experiences and may have relevance to a wider section of the brain injury population.

We also employed strategies such as an audit trail, peer review and a reflective journal to support the analysis process and credibility of the findings.

However, whilst our sample was diverse in several aspects, we had no participants from ethnic minority backgrounds. There is evidence to suggest cultural differences in how fatigue is understood and so our findings can only be generalised to ABI survivors of similar cultural backgrounds [57].

Our participants also experienced other health conditions and were taking a wide range of medications, some of which might exacerbate fatigue. However, this is reflective of clinical 
practice in that comorbidities are frequent after $\mathrm{ABI}[58,59]$ and fatigue is unlikely to be the sole difficulty.

\section{Conclusions and implications for further research and practice}

This study adds to our understanding of fatigue experienced by individuals with ABI by highlighting the complex interactions between types of fatigue, coping strategies, everyday activities, and environments. As such this study suggests potential areas for health professionals to consider when supporting individuals with $A B I$ to manage their fatigue. Understanding different types of fatigue and how these are exacerbated by activities and environments, is necessary when advising on self- management strategies, particularly in relation to balancing fatigue with daily activity. Feeling unmotivated as part of the fatigue experience is important to consider when educating ABI survivors and carers about managing fatigue, as it helps to explain behaviour that might be construed as laziness, particularly if individuals fluctuate in what they feel able to do.

The role of sleep both as a proactive and reactive strategy also needs to be considered in relation to an individual's quality of sleep at night and the impact on everyday activities [21]. $\mathrm{ABI}$ survivors may need guidance on how to develop strategies that can be more easily applied in social settings. Furthermore, the use of personalised and nuanced coping strategies may help ABI survivors to participate in a wider range of daily activities and to increase their physical activity levels. In addition, recognising the importance of participation in meaningful activities and use of social support may help individuals in breaking the negative cycle of fatigue and inactivity.

Our findings reinforce the view that fatigue is a multidimensional concept and that fatigue assessment should reflect the daily variability of fatigue and the contexts in which it occurs. 
We suggest that fatigue assessment should delineate between fatigue as a trait and "in-themoment" experiences of fatigue. There is now a need to move beyond the current limitations of fatigue scales and paper diaries and develop alternative approaches. In-the-moment assessment of fatigue within the context of daily life may be more beneficial in guiding selfmanagement strategies, serve to increase ABI survivors' self- knowledge of fatigue patterns and triggers, and thereby facilitate faster and more effective adjustment to living with fatigue [19].

\section{Acknowledgements}

We would like to thank Headway for their support in allowing us to attend meetings to explain the nature of the study and to invite members to take part in it.

\section{Disclosure Statement}

No potential conflict of interest was reported by the authors

\section{References}

1. Menon D, Byrant C. Time for change in acquired brain injury. The Lancet Neurology. 2019 2019/01/01;18(1):28.

2. Headway. Acquired Brain Injury 2016-2017: statistics based on UK admissions. 2019. Available from: https://www.headway.org.uk/about-brain-injury/furtherinformation/statistics/

3. Ponsford JL, Ziino C, Parcell DL, et al. Fatigue and sleep disturbance following traumatic brain injury - Their nature, causes, and potential treatments. The Journal of Head Trauma Rehabilitation. 2012;27(3):224-233.

4. Acciarresi M, Bogousslavsky J, Paciaroni M. Post-stroke fatigue: epidemiology, clinical characteristics and treatment. Eur Neurol. 2014;72(5-6):255-61.

5. Elf M, Eriksson G, Johansson S, et al. Self-Reported Fatigue and Associated Factors Six Years after Stroke. PLoS One. 2016;11(8):e0161942.

6. Ponsford JL, Downing MG, Olver J, et al. Longitudinal follow-up of patients with traumatic brain injury: outcome at two, five, and ten years post-injury. Journal Of Neurotrauma. 2014;31(1):64-77. 
7. De Doncker WD, R, Ormstad HK, A. Mechanisms of poststroke fatigue. Journal of Neurology, Neurosurgery \& Psychiatry. 2018 2018-03-01;89(3).

8. Mollayeva T, Kendzerska T, Mollayeva S, et al. A systematic review of fatigue in patients with traumatic brain injury: The course, predictors and consequences. Neuroscience and Biobehavioral Reviews. 2014 Nov;47:684-716.

9. Chaudhuri A, O Behan P. Fatigue in Neurological Conditions. The Lancet. 2004 [cited 978-988 p.]. DOI:doi:10.1016/S0140-6736(04)15794-2 http://www.sciencedirect.com/science/article/pii/S0140673604157942

10. Leavitt VMD, J. Central Fatigue: Issues related to Cognition, Mood and Behaviour; and Psychiatric Diagnoses. PM\&R. 2010;2(5):332-337.

11. Cantor JB, Gordon W, Gumber S. What is post TBI fatigue? Neurorehabilitation. 2013;32(4):875-883.

12. Feigin VL, Barker-Collo S, Parag V, et al. Prevalence and predictors of 6-month fatigue in patients with ischemic stroke: a population-based stroke incidence study in Auckland, New Zealand, 2002-2003. Stroke (00392499). 2012;43(10):2604-2609.

13. Chaudhuri A, Behan P. Fatigue and basal ganglia. Journal of the Neurological Sciences. 2000;179(1-2):34--42.

14. Leavitt VM, DeLuca J. Central fatigue: issues related to cognition, mood and behavior, and psychiatric diagnoses. Pm r. 2010 May;2(5):332-7.

15. Andersen $G$, Christensen $D$, Kirkevold $M$, et al. Post-stroke fatigue and return to work: a 2-year follow-up. Acta neurologica Scandinavica. 2012;125(4):248-53.

16. Jackson S, Mercer C, Singer BJ. An exploration of factors influencing physical activity levels amongst a cohort of people living in the community after stroke in the south of England. Disabil Rehabil. 2018 Feb;40(4):414-424.

17. Nicholson SL, Donaghy $M$, Johnston $M$, et al. A qualitative theory guided analysis of stroke survivors' perceived barriers and facilitators to physical activity. Disabil Rehabil. 2014;36(22):1857-68.

18. Ezekiel L, Collett J, Mayo NE, et al. Factors Associated With Participation in Life Situations for Adults With Stroke: A Systematic Review. Arch Phys Med Rehabil. 2018 Jul 5.

19. White JH, Gray KR, Magin P, et al. Exploring the experience of post-stroke fatigue in community dwelling stroke survivors: a prospective qualitative study. Disabil Rehabil. 2012;34(16):1376-84.

20. Eilertsen $\mathrm{G}$, Ormstad H, Kirkevold M. Experiences of poststroke fatigue: qualitative meta-synthesis. Journal of advanced nursing. 2013;69(3):514-25.

21. Theadom A, Rowland V, Levack W, et al. Exploring the experience of sleep and fatigue in male and female adults over the 2 years following traumatic brain injury: a qualitative descriptive study. BMJ Open. 2016 Apr 08;6(4):e010453.

22. Duncan F, Lewis SJ, Greig CA, et al. Exploratory longitudinal cohort study of associations of fatigue after stroke. Stroke (00392499). 2015;46(4):1052-1058.

23. Flinn $\mathrm{Na}$, Stube JE. Post-stroke fatigue: qualitative study of three focus groups. Occupational therapy international. 2010;17(2):81-91. 
24. Piercy KL, Troiano RP, Ballard R, et al. The Physical Activity Guidelines for Americans. JAMA. 2019;320(19):2020-2028.

25. Durcan D, Bell R. Local action on health inequalities: reducing social isolation across the lifecourse. London: UCL Institute of Health Equity; 2015.

26. Party ISW. National Clinical Guideline for Stroke. In: Physicians RCo, editor. 5th ed. London: Royal College of Physicians; 2016.

27. Barker-Collo S, Feigin VL, Dudley M. Post stroke fatigue--where is the evidence to guide practice? The New Zealand Medical Journal. 2007;120(1264):U2780U2780.

28. Marshall S, Bayley M, McCullagh S, et al. Updated clinical practice guidelines for concussion/mild traumatic brain injury and persistent symptoms. Brain Inj. 2015;29(6):688-700.

29. Wylie GR, Flashman LA. Understanding the interplay between mild traumatic brain injury and cognitive fatigue: models and treatments. Concussion. 2017 Dec;2(4).

30. Huguet A, McGrath $P$, Wheaton $M$, et al. Testing the Feasibility and Psychometric Properties of a Mobile Diary (myWHI) in Adolescents and Young Adults with Headaches. JMIR mHealth uHealth. 2015 [cited 1-21 p.].

31. Schwandt T. Constructivist, Interpretativist Approaches to Human Inquiry. In: Denzin N, Lincoln Y, editors. From the Landscape of Qualitative Research: Theories and Issues. Thousand Oaks: Sage; 1998. p. 221-259.

32. Rubin H, Rubin I. Qualitative Interviewing: the art of hearing data. 3rd ed. Thousand Oaks.: Sage; 2012 2018-11-24.

33. Krupp LB, LaRocca NG, Muir-Nash J, et al. The fatigue severity scale. Application to patients with multiple sclerosis and systemic lupus erythematosus. Arch Neurol. 1989 Oct;46(10):1121-3.

34. Herdman M, Gudex C, Lloyd A, et al. Development and preliminary testing of the new five-level version of EQ-5D (EQ-5D-5L). Qual Life Res. 2011 Dec;20(10):1727-36.

35. Lerdal A, Kottorp A. Psychometric properties of the Fatigue Severity ScaleRasch analyses of individual responses in a Norwegian stroke cohort. International journal of nursing studies. 2011;48(10):1258-65.

36. Whitehead $\mathrm{L}$. The measurement of fatigue in chronic illness: a systematic review of unidimensional and multidimensional fatigue measures. J Pain Symptom Manage. 2009 Jan;37(1):107-28.

37. Ziino C, Ponsford J. Measurement and prediction of subjective fatigue following traumatic brain injury. Journal Of The International Neuropsychological Society: JINS. 2005;11(4):416-425.

38. Valko PO, Bassetti CL, Bloch KE, et al. Validation of the Fatigue Severity Scale in a Swiss Cohort. Sleep. 2008 Nov 1;31(11):1601-7.

39. Janssen MF, Pickard AS, Golicki D, et al. Measurement properties of the EQ-5D$5 \mathrm{~L}$ compared to the EQ-5D-3L across eight patient groups: a multi-country 
study. Qual Life Res. 2013 [cited 1717-27 p.]. DOI:10.1007/s11136-012-0322-4 http://dx.doi.org/10.1007/s11136-012-0322-4

40. Ritchie J, Lewis J, McNaughton Nicholls C, et al. Qualitative Research Practice. 2nd ed. London: Sage Publications; 2013.

41. Gale N, Heath G, Cameron E, et al. Using the framework method for the analysis of qualitative data in multi-disciplinary health research BMC Medical Research Methodology. 2013 [cited 117-124 p.].

42. Palstam A, Törnbom M, Sunnerhagen KS. Experiences of returning to work and maintaining work 7 to 8 years after a stroke: a qualitative interview study in Sweden. BMJ Open. 2018 [cited. DOI:10.1136/bmjopen-2017-021182 http://dx.doi.org/10.1136/bmjopen-2017-021182

43. Muller T, Apps MAJ. Motivational fatigue: A neurocognitive framework for the impact of effortful exertion on subsequent motivation. Neuropsychologia. 2019 Feb 4;123:141-151.

44. Visser-Keizer AC, Hogenkamp A, Westerhof-Evers HJ, et al. Dutch Multifactor Fatigue Scale: A New Scale to Measure the Different Aspects of Fatigue After Acquired Brain Injury. Archives of Physical Medicine and Rehabilitation. 2015.

45. Beaulieu-Bonneau S, Ouellet M-C. Fatigue in the first year after traumatic brain injury: Course, relationship with injury severity, and correlates.

Neuropsychological Rehabilitation. 2017;27(7):983-1001.

46. Ouellet M-C, Morin CM. Fatigue following traumatic brain injury: Frequency, characteristics, and associated factors. Rehabilitation Psychology. 2006;51(2):140-149.

47. Kirkevold M, Christensen D, Andersen G, et al. Fatigue after stroke: manifestations and strategies. Disabil Rehabil. 2012;34(8):665-70.

48. Bushnik T, Englander J, Wright J. Patterns of fatigue and its correlates over the first 2 years after traumatic brain injury [Article]. Journal of Head Trauma Rehabilitation. 2008 Jan-Feb;23(1):25-32.

49. van de Port IGL, Kwakkel G, Schepers VPM, et al. Is fatigue an independent factor associated with activities of daily living, instrumental activities of daily living and health-related quality of life in chronic stroke? Cerebrovascular Diseases (Basel, Switzerland). 2007;23(1):40-45.

50. Cantor JB, Ashman T, Gordon W, et al. Fatigue after traumatic brain injury and its impact on participation and quality of life. J Head Trauma Rehabil. 2008 JanFeb;23(1):41-51.

51. Norlander A, Carlstedt E, Jönsson A-C, et al. Long-Term Predictors of Social and Leisure Activity 10 Years after Stroke. Plos One. 2016;11(2):e0149395e0149395.

52. Crosby GA, Munshi S, Karat AS, et al. Fatigue after stroke: frequency and effect on daily life. Disabil Rehabil. 2012;34(8):633-7.

53. Ormstad H, Eilertsen G. A biopsychosocial model of fatigue and depression following stroke. Medical Hypotheses. 2015;85(6):835-841. 
54. Rochette A, Tribble DS, Desrosiers J, et al. Adaptation and coping following a first stroke: a qualitativ... : International Journal of Rehabilitation Research. International Journal of Rehabilitation Research. 2006;29(3):247-249.

55. Buono VL, Corallo F, Bramanti P, et al. Coping strategies and health-related quality of life after stroke: [research-article]. http://dxdoiorg/101177/1359105315595117. 2015 2015-07-27.

56. Norrie J, Heitger M, Leathem J, et al. Mild traumatic brain injury and fatigue: A prospective longitudinal study. Brain Injury. 2010;24(13/14):1528-1538.

57. Karasz A, McKinley PS. Cultural differences in conceptual models of everyday fatigue: a vignette study. J Health Psychol. 2007 Jul;12(4):613-26.

58. Chan VM, T. Ottenbacher, K.J. Colantonio,A. Clinical profile and comorbidity of traumatic brain injury among younger and older men and women: a brief research notes. BMC Res Notes. 2017 [cited.

59. Fischer $U$, Arnold M, Nedeltchev K, et al. Impact of comorbidity on ischemic stroke outcome. Acta Neurol Scand. 2006 Feb;113(2):108-13. 